Our thanks are due to the Surgeons of Moorfields, Westminster and Central Eye Hospital, High Holborn, for permission to treat their cases. We are indebted to Mr. W. E. S. Bain and Mr. D. Langley for their help in the treatment and for observation of some of these cases, and to Sisters E. Kitchen and P. Hollis. For the photographs we are indebted to Mr. Peter Hansell.

\title{
REFERENCES
}

Ramsden, W. (1902).-Proc. Physiol. Soc., 28, 23.

Peju \& Rajat, (1906).-Compte Rendu Soc. Biol., 65, 477.

Wilson, W. J. (1906).-J. Pathol. \& Bact., 11, 394.

SYMS \& KIRK,(1915). - Quoted after Weinstein and MacDonald.

Foulger, J H. Foshay, L. (1935).-J. Lab. Clin. Med. 20, 1113.

MCKaY, M. E. and Schröder, CH. R. (1935).-Proc. Soc. Exp. Biol. 74, 77.

Robinson, W. (1936).-Am. J. Surg. 33, 192.

WEINSTEIN, L. (1944).-Science, 101, 44.

- and MACDONALD, A. (1946).-J. Immun. 54, 116.

- and Howe, C. W. (1947).-Surg. Gyn. and Obst., 84, 912.

Williams, J. L. D. (1946).-J. O. L. O., 41, 251.

Paterson, E. and Haddow, A, , etc. (1.946).-Lancet, 2, 677.

HADdow, A. (1948).-Proc. Roy. Soc. Med. 58, 48.

\section{THE RELATIVE IMPORTANCE OF, DIRECT AND INDIRECT OPHTHALMOSCOPIC EXAMINATION IN THE TREATMENT OF RETINAL DETACHMENT*}

BY

\author{
H. ARRUGA \\ BARCÉLONA
}

IT is essential to employ both methods of ophthalmoscopy to obtain the highest possible percentage of successes in the surgical treatment of retinal detachment. I have seen on my travels that many colleagues employ one method to the exclusion of the other, and that in some countries the majority of the ophthalmologists use one method almost exclusively. If , we grant the enormous importance of ophthalmoscopic examination in the treatment of retinal detachment, we must also make as complete an examination as possible by this method. I have seen colleagues who, though excellent clinicians and surgeons, only reached 55 per cent. of successes in these operations, owing, in my opinion, to the exclusive use of direct ophthalmoscopy as a mode of operative orientation.

These facts decided me to prepare the statistics of 200 unselected cases of my own, which'I had classified in the following four groups:-

The first group includes those cases in which tears were visible to either method of examination. In the second group tears were visible only to indirect ophthalmoscopy, and in the third only visible

- Received for publication, May 27, 1949. 
to direct ophthalmoscopy. The fourth group includes cases in which tears were invisible to both methods.

The figures are as follows:-

Cases with tears which were visible by both methods

Cases with tears which were visible only by indirect ophthalmoscopy $\ldots{ }^{\prime}, \ldots \quad \ldots \quad \ldots \quad \ldots$

Cases with tears which were visible only by direct ophthalmoscopy $\quad \ldots \quad \begin{array}{llllll} & \ldots & \ldots & \ldots & \ldots & 3\end{array}$

Cases with tears which were invisible to both methods 18

Tótal $\overline{200}$

Of the 18 cases forming the fourth group, 11 were extremely old ones, with opaque vitreous or other opacities, and 4 of them were clearly cases of exudative choroiditis.

The advantage of indirect ophthalmoscopy can be deduced from these statistics. Direct ophthalmoscopy is an excellent method for appreciating doubtful details, such as haemorrhage, and in order to measure differences of retinal level. Indirect ophthalmoscopy, however, with its larger field, better view of the periphery, and the possibility of employing a high light intensity of 150-200 candle power, is the method which should be preferred, although one should not use it exclusively. Pictures are reproduced of six cases in which it was possible to make a drawing of the retinal tear. In the remaining cases the tear was too obscure to be truly represented in any drawing without falsifying the reality, and these latter cases formed the majority.

\section{Exampies of Cases With Tears Difficult to Diagnose}

1. Tear near the ora serrata only visible with the indirect method. This represents a recurrence in an operated case. It was cured by diathermy.

2. Between the folds of the retina appeared a red line like a vessel. This sometimes disappeared, and it was only possible by the direct method to verify that it was a tear. During the operation the tear was half opened.

3. In the centre of the figure in a fold of the retina a tear with pigmented borders was recognised through the difference in level of its borders, no red coloration being seen. During the operation the tear was easily visible.

4. Detachment with large lateral disinsertion. The macula appeared perforated, but with direct ophthalmoscopy it was revealed as a cystoid degeneration without difference of level.

5. Tear only visible by indirect ophthalmoscopy, difficult to verify because there was a shallow detachment of the adjacent retina. The operative closure of the tear confirmed this diagnosis. 


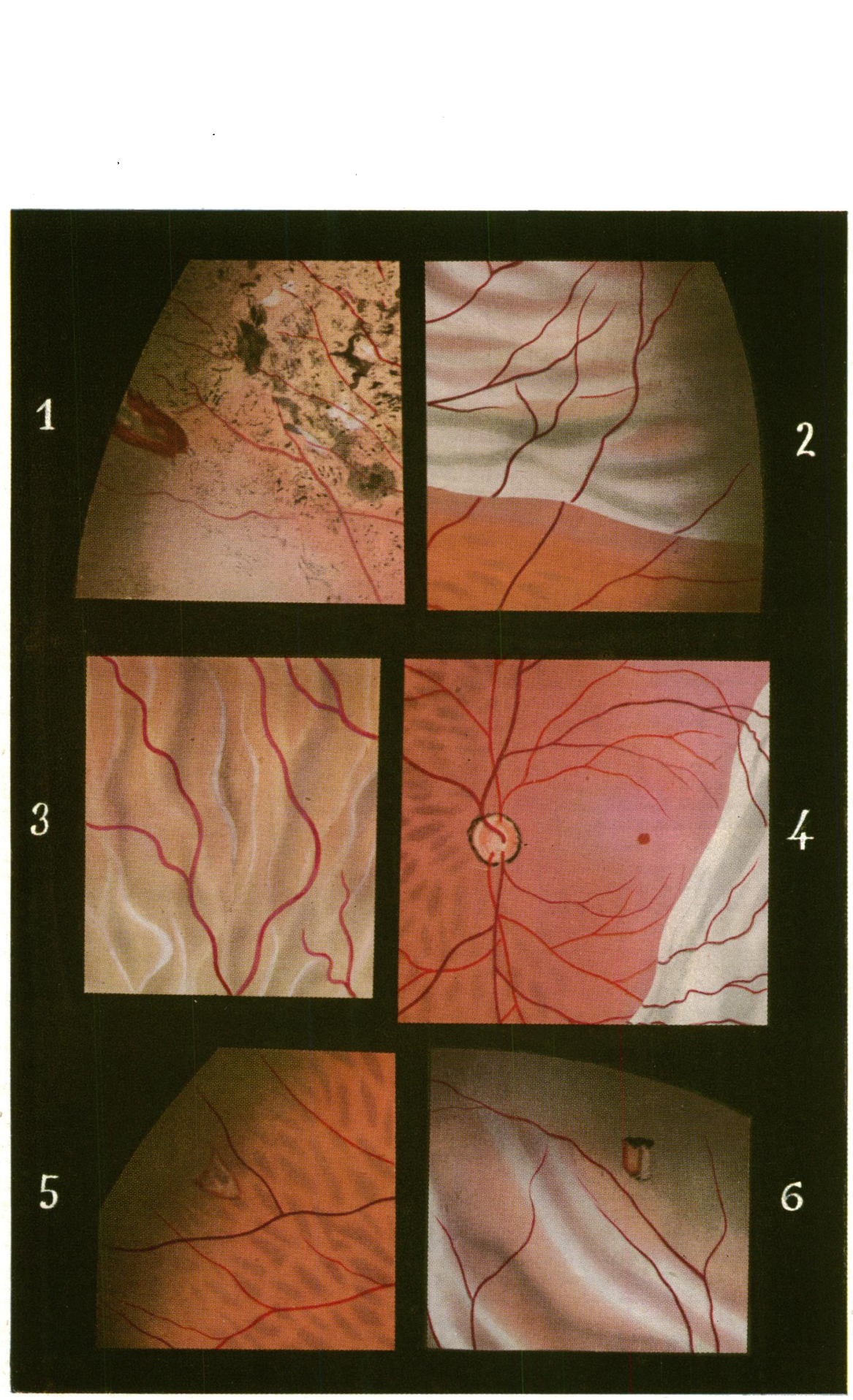

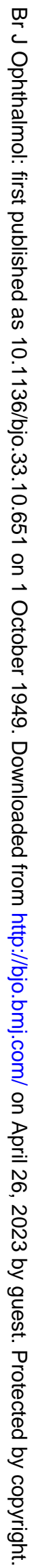


6. Tear near the ora serrata invisible with direct ophthalmoscopy. Except for the folds of the retina, it appeared like a spot of chorioretinitis. Closure of the hole cured the detachment.

\section{Professor Dr. JOSEF MELLER (Vienna)}

It is pleasant to salute outstanding men, and readers will have noticed that several recent articles in the Journal were dedicated to the subject of this address. On behalf of his British colleagues. we thank Professor Meller for the example he has set, and in offer. ing him congratulations on his seventy-fifth birthday (October 22, 1949) we wish him pleasant days in retirement. His work and character will be remembered for many years. On the occasion of the seventieth birthday of Ernst Fuchs, Meller wrote about his predecessor: "His name shines forth in our science as that of his great teacher von Arlt." Meller in his turn has carried on the outstanding work of the Vienna School.

Since 1898 until his retirement in October, 1944, he worked at the Eye Clinic of Vienna, except for a three-year period (1915 to 1918 ), when he was " ordinary " professor of ophthalmology at the Imperial and Royal University of Innsbruck, to which he had been appointed by the Emperor Francis Joseph. In 1918 he was appointed "ordinary" professur of Ophthalmology at the Imperial and Royal University in Vienna, but by a letter from the German Reichminister for Science and Education, Berlin, dated May 10, 1944, he was relieved of the post of leader and teacher in the Vienna Eye Clinic " in the interest of later development at the high schools," and he retired from his position on October 1, 1944.

Unfortunately he seldom visited this country, although he had a good command of English, but he attended the 50th Annual Congress of the Ophthalmological Society of the United Kingdom at London in 1930 and became known to many of the participants who recollect his qualities of sincerity, modesty and geniality. He was also seen at the Oxford Congress a few times, and contributed to important discussions at the meetings of that body. Many will remember his delivery of the 1934 Doyne Memorial Lecture, which emphasised the continental view that iridocyclitis is often tuberculous in nature (as is now agreed in this country). He also reported that in some such cases tubercle bacilli may be recovered from the blood and from the eye, and argued that sympathetic ophthalmia is also probably tuberculous-dicta nọt accepted without considerable reserve. 